\title{
Copaiba oil effect on experimental jaw defect in Wistar rats ${ }^{1}$
}

\author{
Priscilla Flores Silva', Marcus Vinicius Henriques Brito", Flávia Sirotheau Correa Pontes ${ }^{\mathrm{III}}$, Suzana Rodrigues Ramos ${ }^{\mathrm{IV}}$, Laís \\ Cordeiro Mendesv , Louize Caroline Marques Oliveira ${ }^{\mathrm{VI}}$
}

DOI: http://dx.doi.org/10.1590/S0102-86502015002000006

IFellow Master Degree, Postgraduate Program in Clinical Dentistry, Federal University of Para (UFPA), Brazil. Conception, design, intellectual and scientific content of the study.

${ }^{I I} \mathrm{PhD}$, Full Professor, Medical School, State University of Para (UEPA), Brazil. Conception and design of the study, analysis of data, critical revision. IIIPhD, Associate Professor, Dentistry School, UFPA, Belem-PA, Brazil. Histopathogical examinations, analysis of data, critical revision.

${ }^{\text {IV }}$ Graduate Medical Student, UEPA, Belem-PA, Brazil. Acquisition of data

${ }^{\mathrm{v}}$ Graduate Dentistry Student, UFPA, Belem-PA, Brazil. Acquisition of data, manuscript writing.

${ }^{\mathrm{VI}}$ Graduate Medical Student, UFPA, Belem-PA, Brazil. Acquisition of data.

\begin{abstract}
PURPOSE: To evaluate the effects of copaiba oil on jaw defects repair in Wistar rats treated with bioglass or adipose tissue.

METHODS: A jaw defect was randomly created in forty-two rats and filled with bioglass or adipose tissue. The two groups (Gbio and Gcell) were subdivided in three subgroups with seven animals each according to gavage administration: control (distillated water), oil (copaiba oil) and melox (meloxicam). Euthanasia was performed after forty post-operative days. The bone formation was analyzed regarding the histological aspects.

RESULTS: The osteoclasts activity was observed only in four subgroups $(\mathrm{p}=0.78)$. Regarding the osteoblasts presence, it was very similar between the subgroups, the difference was due to Gcell-melox $(\mathrm{p}=0.009)$ that presented less osteoblastic activity. The inflammatory cells were more evident in Gcell-melox subgroup, however, there was no difference in comparison with the other subgroups ( $\mathrm{p}=0.52$ ). Bone formation was observed in all subgroups, just two animals showed no bone formation even after 40 days. More than $50 \%$ of bone matrix mineralization was observed in 56\% (23 animals) of the analyzed areas. The bone matrix mineralization was not different between subgroups $(\mathrm{p}=0.60)$.
\end{abstract}

CONCLUSIONS: The subgroups that received copaiba oil showed bone repair, although not statistically significant in comparison to subgroups treated whit meloxicam or controls. Copaiba oil administered by gavage had no effect on bone repair in this experimental model.

Key words: Plants, Medicinal. Bone Regeneration. Anti-Inflammatory Agents. Rats. 


\section{Introduction}

Bone substitutes are frequently used in dentistry to augment bone tissue or to fill bone defects. Among bone grafts, various types of hydroxyapatite, deproteinized bovine bone matrix and synthetic glasses have been largely tested on bone tissue engineering ${ }^{1}$. Due to its limited availability and morbidity, the autogenous bone graft as well as an inadequate potential osteoinductive and osteoconductive of the allograft, research has been conducted to develop new bone substitutes to improve bone healing ${ }^{2}$.

Bioglass is a bioactive particulate material made of granules consisting of silicon, sodium, calcium and phosphorus, able to bond to bone and connective tissue. It may allow for more rapid repair and regeneration of bone than other synthetic grafting materials by forming a layer of hydroxyl-carbonate apatite on its surface equivalent to the mineral phase of human bone. It has been used in a few experimental and clinical studies to treat different types of bone defect and it was claimed that bioglass promoted bone formation ${ }^{1,3}$.

Mesenchymal stem cells reside in many tissues, including bone marrow, adipose tissue, synovial fluid, dermis and muscle. They can differentiate along a variety of cell lineages that can be used to regenerate bone and other tissues. Adipose-derived mesenchymal stem cells have been identified as a source of multipotent cells that have osteogenic differentiation potential in vitro and in vivo and is the most abundant and accessible source of adult stem cells, which is significantly higher in adipose tissue in comparison to bone marrow ( $2 \%$ vs. $0.002 \%)^{2}$. Moreover, they have been reported to have low immunogenicity. The studies have demonstrated that adipose tissue stem cells are capable of exhibiting good attachment properties to most material surfaces and have the capacity to differentiate into osteoblastic-like cells in vitro and in vivo ${ }^{4,5}$.

Copaiba oil has been widely targeted research in order to prove its therapeutic characteristics. In several studies it had effective pharmacological properties in surgical procedures, wound healing, inflammatory processes, such as antioxidant, antitumor and even as a bacteriostatic substance ${ }^{6-12}$. Yasojima et $a l .{ }^{11}$ analyzed the effect of copaiba oil in correction of abdominal wall defects treated with polypropylene/polyglecaprone meshes in rats. The authors concluded that copaiba oil administered by gavage reduced the amount of abdominal adhesions and accelerated the formation of collagen fibers without damaging the early stages of healing. Nogueira Neto et al. ${ }^{12}$ evaluated changes that occurred in rats with experimental endometriosis treated with copaiba oil. They observed a significant increase between the end and the initial volume the control group, whereas the group treated with copaiba oil had a marked reduction in endometrial growth. These results led the authors to conclude that copaiba oil can be an alternative potential treatment for endometriosis.

Many anti-inflammatory substances are currently used in clinical practice after bone grafting and fractures to minimize clinical postoperative symptoms, nevertheless their effect in bone tissue can minimize or delay the incorporation process and affect bone tissue repair ${ }^{13-18}$. Despite its proven anti-inflammatory action, the effect of copaiba oil on bone tissue repair is not well established ${ }^{20}$. The aim of this experimental study was to evaluate the copaiba oil influence in experimental bone defects filled with two bone substitutes in rat's jaw by evaluating histologically the composition of formed bone tissue.

\section{Methods}

The project was approved by Ethics Committee in the Use of Animals, State University of Para (UEPA) (Protocol 06/2013).

Forty two Wistar male rats (Rattus norvegicus) aged about 120 days and weight ranging from 250 to $300 \mathrm{~g}$ from the Animal Colony of the Experimental Surgery Laboratory of UEPA were used. They were kept in a controlled environment (light cycle 12/12 h and temperature of $23^{\circ} \mathrm{C}$ ), with food and water ad libitum. The animals were randomly distributed into two groups (Gbio and Gcell) and subdivided in three subgroups each with seven animals (Figure 1).

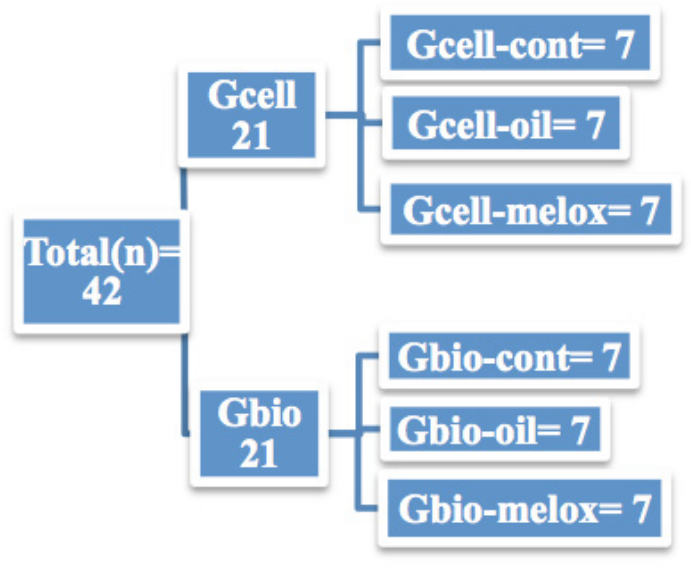

FIGURE 1 - Groups and subgroups distribution.

The procedure was performed by a single surgeon. The animals were anesthetized with ketamine hydrochloride (70 $\mathrm{mg} / \mathrm{Kg}$ ) and xylazine hydrochloride $(10 \mathrm{mg} / \mathrm{Kg})$, administered intraperitoneally. Once animals' anesthesia was confirmed, the skin 
was shaved and the surgical site was disinfected. Subsequently, was performed an "U" (7X14mm) incision and a full-thickness flap was raised to expose the external side of jaw. Under continuous saline irrigation, a slowly rotating round burr was used to create circular defects $2.5 \mathrm{~mm}$ in diameter in the region anterior to the jaw angles on right side of the jaw of each rat. (Figure 2)

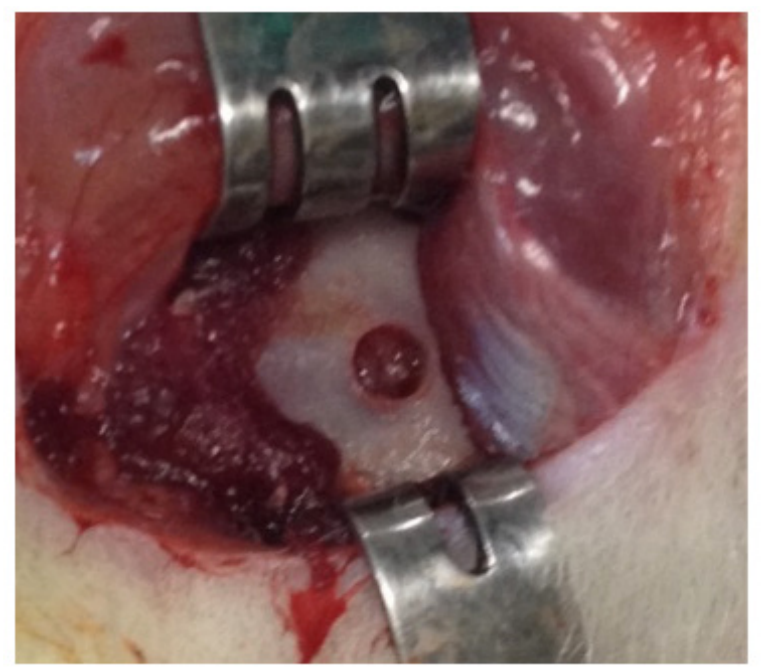

FIGURE 2 - Bone defect in rat jaw.

Study design

The bone defects were filled with either bioglass (CeelBio) or adipose tissue according to the groups (Figure 3 ). In Cell subgroups (Gcell-control, Gcell-oil, Gcell-melox), shave, antisepsis and a linear $5 \mathrm{~mm}$ incision was realized in the inguinal region of the animal and then $9 \mathrm{~mm}^{3}$ of the subcutaneous adipose tissue was dissected and removed (Figure 4). The adipose tissue was fragmented and washed with saline solution according to technique described by Gomes et al. ${ }^{19}$. The bioglass subgroups (Gbio-control, Gbio-oil, Gbio-melox) were grafted with bioglass (granulation of $0.25 \mathrm{~mm}$ ) provided by the company CeellBio. After the procedures, the wounds were closed with 3-0 nylon sutures.
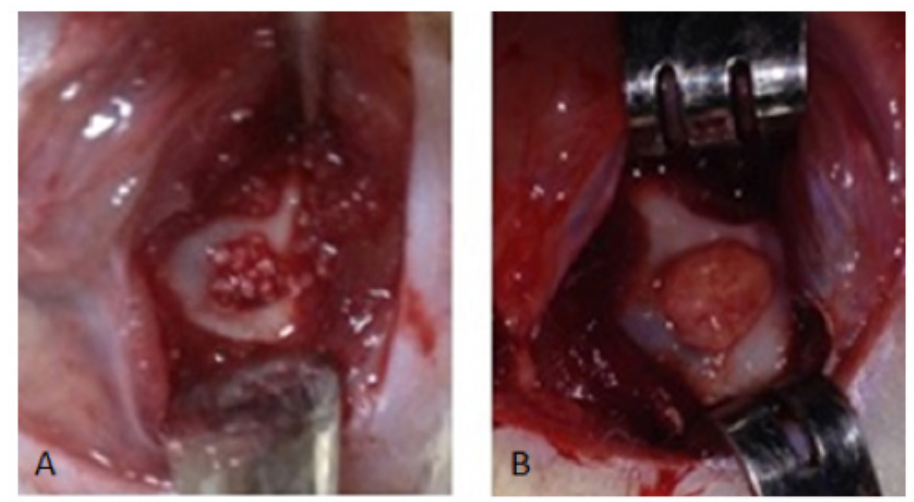

FIGURE 3 - A. Bone defect filled with bioglass. B. Bone defect filled with adipose tissue.

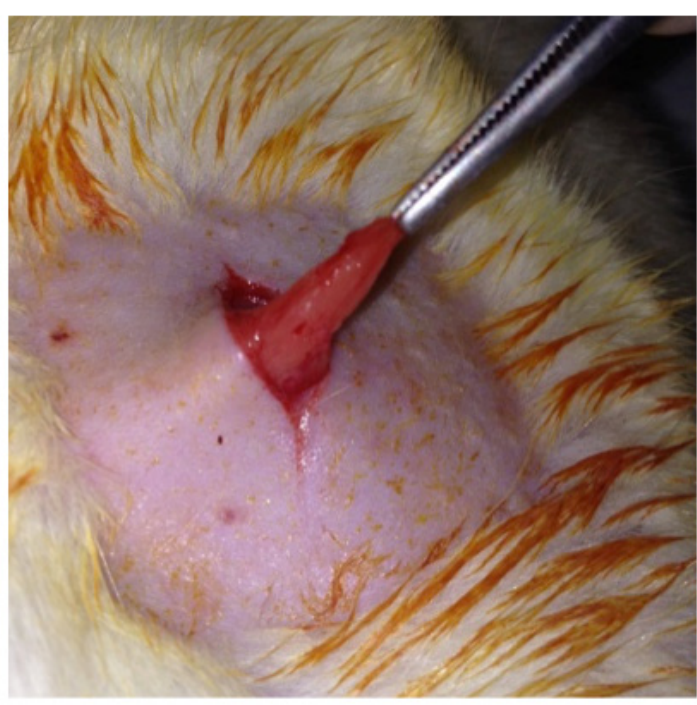

FIGURE 4 - Inguinal adipose tissue removal.

\section{Gavage procedures}

On the fifth postoperative day, the gavage was initiated and performed for seven days, once a day, with three different substances according to subgroups: Gbio-control and Gcell-control received $0.6 \mathrm{ml} / \mathrm{kg} /$ day distillated water; Gbiooil and Gcell-oil received $0.6 \mathrm{ml} / \mathrm{kg} /$ day copaiba oil in natura (EMBRAPA); Gbio-melox and Gcell-melox received $0.25 \mathrm{mg} /$ $\mathrm{kg} /$ day meloxicam $\left(\right.$ Medley ${ }^{\circledR}$ ) diluted in distillated water $0.6 \mathrm{ml} /$ kg (Table 1).

TABLE 1 - Schematic time line (in days) of the experimental study stages.

\begin{tabular}{lcccc}
\hline $\begin{array}{l}\text { Groups } \backslash \\
\text { Time-line }\end{array}$ & Day 0 & $\begin{array}{c}\text { Day 5 - } \\
\text { Day 11 }\end{array}$ & $\begin{array}{c}\text { Day 12 - } \\
\text { Day 39 }\end{array}$ & Day 40 \\
\hline All groups & $\begin{array}{c}\text { Surgical } \\
\text { procedure }\end{array}$ & Gavage & $\begin{array}{c}\text { Observation } \\
\text { period }\end{array}$ & Euthanasia \\
\hline
\end{tabular}

Forty days after surgical procedure the animals were submitted to euthanasia procedure by anesthetic's overdoses.

The right side of the jaw was removed for histological analysis (Figure 5). The fragments were fixed in 10\% formalin for 48 hours and decalcified in 10\% nitric acid. So, after included in paraffin, they were processed to obtain $5 \mu \mathrm{m}$ thick serial sections, which were made in buccolingual direction to compose histological blades. 


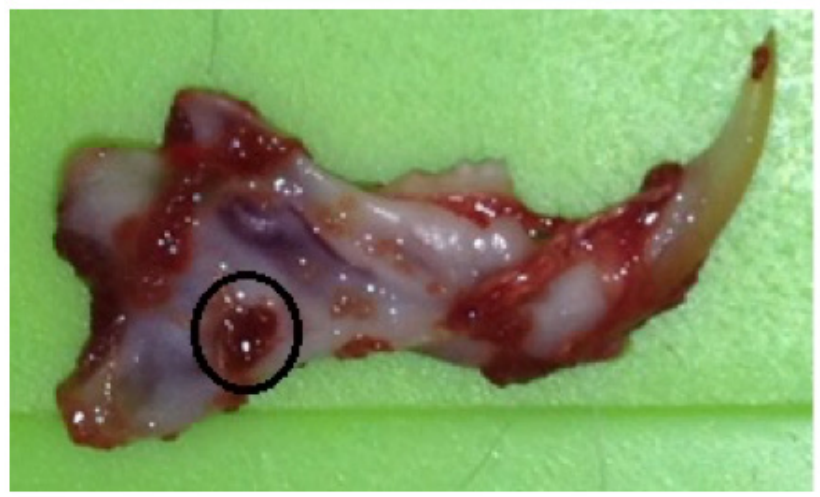

FIGURE 5 - Dissected rat jaw. The circle identifies previous bone defect area.

The specimens were stained with hematoxylin/eosin and Masson's trichrome. The quality of new bone and inflammatory response in the defect site were evaluated in histological analysis by light microscopy with x40 magnification (Nikon Eclipse E200, Tokyo, Japan).

Bone formation parameters (scores of osteoclasts, osteoblasts, inflammatory cells and bone matrix) were established to histological evaluation. The osteoprogenitor bone cells presence (osteoblasts) and activity (osteoclasts -1 : inactivity, 2: little, 3 : much activity), the inflammatory infiltrate (1: absent, 2: mild, 3: moderate, 4: intense) and the mineralization of bone matrix (1: absence, 2: 0 to $50 \%$ bone formation, 3: $>50 \%$ bone formation) were analyzed and categorized for each subgroup. A previous trained, single blinded examiner was able to establish the scores for each variable set.

\section{Statistical analysis}

The non-parametric Kruskal-Wallis test was used to evaluate the statistical differences between the subgroups, followed by Dunn's test considering a p-value less than 0.05 as significant. The software Bioestat 5.3 ${ }^{\circledR}$ was used for statistical analysis.

\section{Results}

During the research, just one animal died after surgical procedure. There were no other complications like dehiscence, fistulae or infection.

The osteoclasts activity was observed only in four groups, it was more evident in Gcell-oil $(\mathrm{p}=0.78)$, however this was not statistically significant (Figure 6). Regarding the osteoblasts presence, the difference was due to Gcell-melox $(p=0.009)$ that presented less osteoblastic activity (Figure 7). The inflammatory cells were present in all groups, however there was no statistical significance $(\mathrm{p}=0.52)$ (Figure 8$)$.

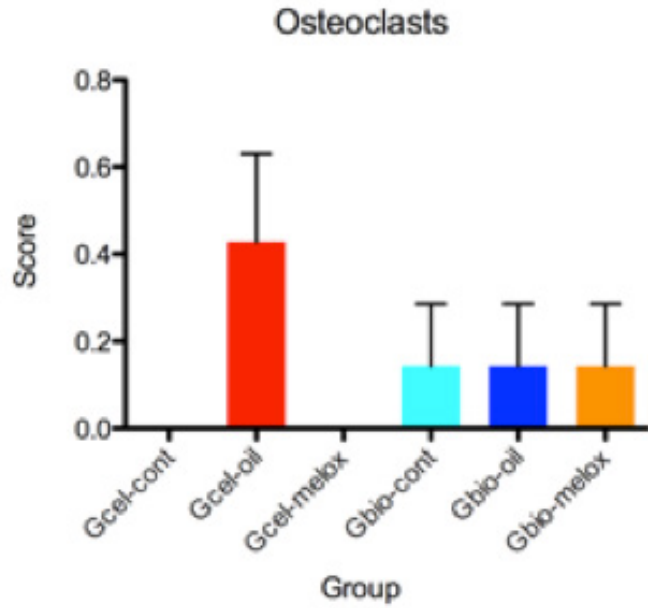

FIGURE 6 - Scores of osteoclasts activity according to each group.

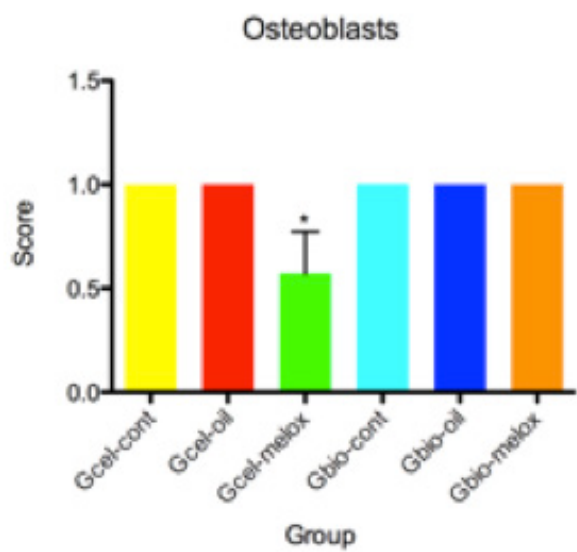

"p<0.05 in relation to Gbio-cont, Gbio-cop, Gbio-melox e Gcel-cop groups

FIGURE 7 - Scores of osteoblasts presence in each group.

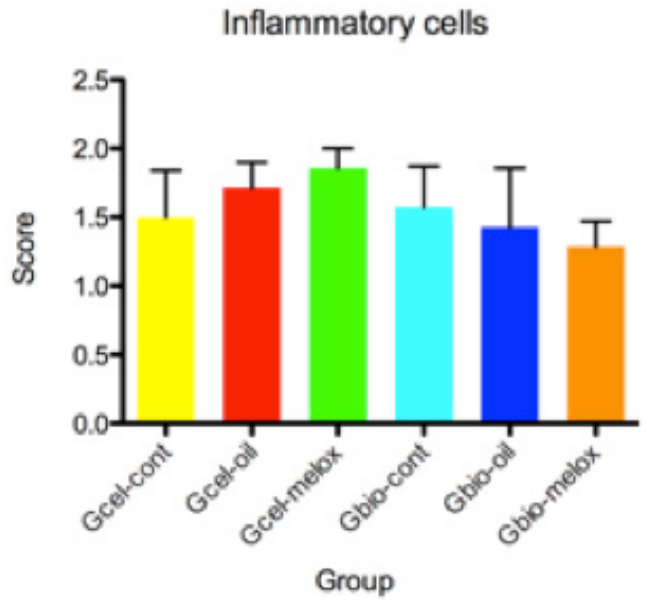

FIGURE 8 - Scores of inflammatory infiltrate in each group. 
Bone formation was observed in all groups, just two animals showed no bone formation even after 40 days. More than $50 \%$ of bone matrix mineralization was observed in 56\% (23 animals) of the analyzed areas. The bone matrix mineralization was not different between groups $(\mathrm{p}=0.60)$ (Figures 9 and 10).

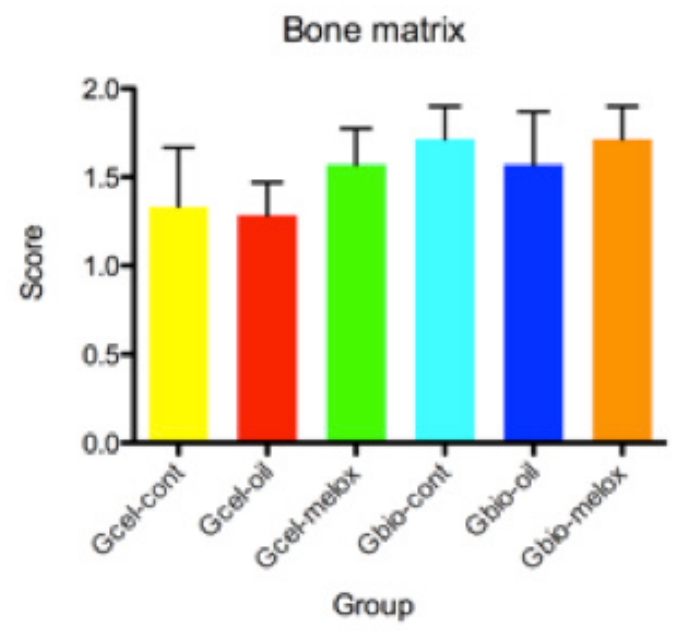

FIGURE 9 - Bone matrix mineralization according to each group.

A

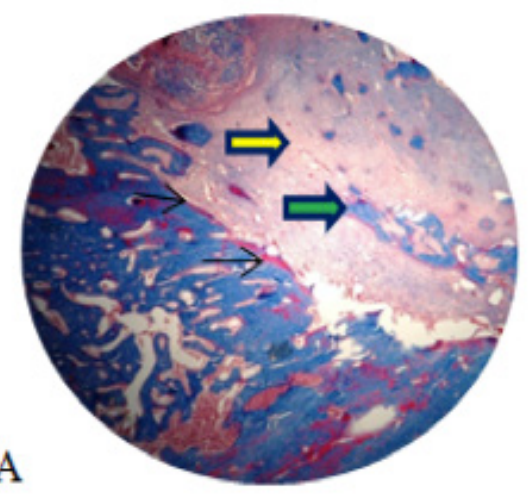

B

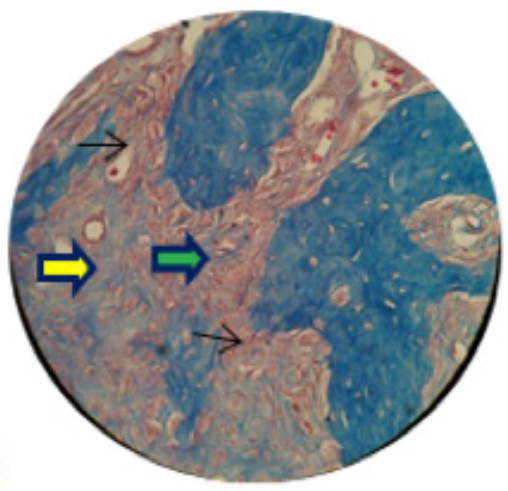

FIGURE 10 - Masson's trichrome staining. Histological specimen analysis of cell (A) and bioglass (B) group. x40 magnification demonstrating presence of remnant material (yellow arrow), osteoblastic activity (black arrow) and newly formed bone matrix (green arrow).

\section{Discussion}

The results from the present study showed that rat jaw grafted with two different biomaterials (bioglass or adipose tissue), obtained, in the 40-day postoperative period, a larger extent of bone matrix deposition, indicating that the groups had similar amounts of mineral deposition in this period of the repair.

The two grafting materials seemed to perform in a similar way concerning their contribution to bone formation which is consistent whit other studies ${ }^{1,2,4,5,20}$. They appeared to be osteoconductive, leading to a mineralized bone matrix with osteoblasts and chronic inflammatory infiltrate.

Through histological evaluation regarding the quality of newly formed bone tissue and comparing the oil, control and melox groups can be inferred that copaiba oil did not interfere with bone formation. To date, just one research correlating copaiba oil to the healing of bone tissue was found. Silva et al. ${ }^{20}$ evaluated the influence of topic and systemic administration of copaiba oil on the alveolar wound healing after tooth extraction in rats. They observed an increased bone neoformation in both groups treated with copaiba oil when compared with placebo group, however, the topic application should be carefully considered because rats treated with topic administration of copaiba oil presented ulcerations and large number of inflammatory cells ${ }^{20}$.

Several other substances with anti-inflammatory properties have been subject of research in this area with contradictory findings ${ }^{13,15,18}$. The studies indicates that nonsteroidal anti-inflammatory drugs (NSAIDs) with higher selectivity to COX-2 showed delayed bone healing and compromised bone density ${ }^{13,15,18}$. Even the glucocorticoids, by inhibition of COX-2 showed a reduced osteogenic differentiation and maturation ${ }^{13}$ while non-selective or NSAIDs with low selectivity did not show changes in bone repair ${ }^{17,18}$.

In the present study, meloxicam, a preferential inhibitor to COX-2, decreased osteoblasts presence when administered in the group that received adipose tissue graft $(\mathrm{p}<0.05)$, which probably affected the synthesis of bone matrix by mesenchymal stem cells, being consistent with studies showing that non-steroidal antiinflammatory drugs affects the quality of bone repair ${ }^{13,15}$. However, there was a good mineralization of bone matrix formed after forty days in this specific group, suggesting the osteoblasts were present but could have a time-limited activity.

The anti-inflammatory activity of copaiba oil has not yet been clearly elucidated. It is believed that such activity is due to the sesquiterpenes which are known to inhibit the activity of receptor activator of nuclear factor kappa b (RANK). RANK is the receptor 
for RANK-Ligand (RANKL) and part of a signaling pathway that regulates osteoclast differentiation and activation. It is associated with bone remodeling and repair, immune cell function, lymph node development, thermal regulation, and mammary gland development Its presence on the osteoclast precursors and mature osteoclasts' surface plays an important role in promoting the differentiation and activation of osteoclasts, leading to bone resorption ${ }^{11,12,20}$. Silva et al. ${ }^{20}$ believe that positive influence of copaiba oil on alveolar bone formation is probably explained by the fact that the sesquiterpenes of copaiba oil inhibited the action of RANK, facilitating the alveolar bone repair.

In the present study the copaiba oil was administered by gavage and the bone formation was histologically evaluated 40 days after the procedure, these two factors could contribute to the results found. Others ways of copaiba oil administration and assessment in shortest and largest period of time, could contribute to different results of this substance influence in jaw bone repair.

\section{Conclusion}

Copaiba oil did not affect the amount of bone formation in jaw defects in rats 40 days after the procedure.

\section{References}

1. Carmagnola D, Abati S, Celestino S, Chiapasco M, Bosshardt D, Lang NP. Oral implants placed in bone defects treated with BioOss, Ostim-Paste or PerioGlas: an experimental study in the rabbit tibiae. Clin Oral Implants Res. 2008 Dec;19(12):1246-53. doi: 10.1111/j.1600-0501.2008.01584.x.

2. Oliveira LC, Giovanini AF, Abuabara A, Klug LG, Gonzaga CC, Zielak JC, Urban CA, Deliberador TM. Fragmented adipose tissue graft for bone healing: histological and histometric study in rabbits' calvaria. Med Oral Patol Oral Cir Bucal. 2013 May;18(3):e510-5. doi: 10.4317/medoral.18407.

3. Stavropoulos A, Kostopoulos L, Nyengaard JR, Karring T. Deproteinized bovine bone (Bio-Oss) and bioactive glass (Biogran) arrest bone formation when used as an adjunct to guided tissue regeneration (GTR): an experimental study in the rat. J Clin Periodontol. 2003 Jul;30(7):636-43. doi: 10.1034/j.1600051X.2003.00093.x.

4. Shi Y, Niedzinski JR, Samaniego A, Bogdansky S, Atkinson BL. Adipose-derived stem cells combined with a demineralized cancellous bone substrate for bone regeneration. Tissue Eng Part A. 2012 Jul;18(13-14):1313-21. doi: 10.1089/ten.tea.2011.0357.

5. Liu G, Zhang Y, Liu B, Sun J, Li W, Cui L. Bone regeneration in a canine cranial model using allogeneic adipose derived stem cells and coral scaffold. Biomaterials. 2013 Apr;34(11):2655-64. doi: 10.1016/j.biomaterials.2013.01.004.

6. Carmona GB, Teixeira RKC, Brito MVH, Pontes FSC, Andrade EHA, Fonseca FP, Costa RMB, Carvalho FM. Effect of andiroba oil on periodontitis in Wistar rats. Acta Cir Bras. 2013 Jun;28(6):430-4. PMID: 23743680.

7. Gelmini F, Beretta G, Anselmi C, Centini M, Magni P, Ruscica M, Cavalchini A, Facino RM. GC-MS profiling of the phytochemical constituents of the oleoresin from Copaifera langsdorffii Desf and a preliminary in vivo evaluation of its antipsoriatic effect. Int J Pharm. 2013 Jan;440(2):170-8. doi: 10.1016/j.ijpharm.2012.08.021.

8. Pieri FA, Mussi MCM, Fiorini JE, Moreira MAS, Schneedorf JM. Bacteriostatic effect of copaiba oil (Copaifera officinalis) against Streptococcus mutans. Braz Dent J. 2012;23(1):36-38. PMID: 22460312.

9. Brito NMB, Brito MVH, Carvalho RKV, Matos LTBM, Lobato RC, Correa SC, Brito RB. The effect of copaiba balsam on Walker 256 carcinoma inoculated into the vagina and uterine cervix of female rats. Acta Cir Bras. 2010 Apr;25(2):176-80. PMID: 20305885.

10. Silva JJL, Guimarães SB, Silveira ER, Vasconcelos PRL, Lima GG, Torres SM, Vasconcelos RC. Effects of copaifera langsdorffii desf on ischemia-reperfusion of randomized skin flaps in rats. Aesthetic Plast Surg. 2009 Jan;33(1):104-9. doi: 10.1007/s00266-008-9263-2.

11. Yasojima EY, Teixeira, RKC, Houat AP, Costa FLS, Silveira EL, Brito MVH, Lopes Filho GJ. Effect of copaiba oil on correction of abdominal wall defect treated with the use of polypropylene/polyglecaprone mesh. Acta Cir Bras. 2013 Feb;28(2):131-5. PMID: 23370927.

12. Nogueira Neto J, Lindoso MJS, Coelho LF, Carvalho RAF, Rodrigues TGPM, Araújo AGP, Girão MJBC, Schor E. Changes in the volume and histology of endometriosis foci in rats treated with copaiba oil (Copaifera langsdorffii). Acta Cir Bras. 2011;26 Suppl 2:20-4. PMID: 22030810.

13. Li J, Wang X, Zhou C, Liu L, Wu Y, Wang D, Jiang H. Perioperative glucocorticosteroid treatment delays early healing of a jaw wound by inhibiting osteogenic differentiation. Injury. 2012 Aug;43(8):12849. doi: 10.1016/j.injury.2012.04.014.

14. Iwamoto J, Seki A, Sato Y, Matsumoto H, Tadeda T, Yeh JK. Vitamin $\mathrm{k} 2$ promotes bone healing in a rat femoral osteotomy model with or without glucocorticoid treatment. Calcif Tissue Int. 2010 Mar;86(3):234-41. doi: 10.1007/s00223-010-9333-8.

15. Dimmen S, Nordsletten L, Madsen JE. Parecoxib and indomethacin delay early fracture healing: a study in rats. Clin Orthop Relat Res. 2009 Aug;467(8):1992-9. doi: 10.1007/s11999-009-0783-0.

16. Akritopoulos P, Papaioannidou P, Hatzokos I, Haritanti A, Iosifidou E, Kotoula M, Mirtsou-Fidani V. Parecoxib has non-significant long-term effects on bone healing in rats when administered for a short period after fracture. Arch Orthop Trauma Surg. 2009 Oct;129(10):1427-32. doi: 10.1007/s00402-008-0707-6.

17. Teófilo JM, Giovanini GS, Fracon RN, Lamano T. Histometric study of alveolar bone healing in rats treated with the nonsteroidal antiinflammatory drug nimesulide. Implant Dent. 2011 Apr;20(2):e7-13. doi: 10.1097/ID.0b013e31820fbacf.

18. Cappello T, Nuelle JAV, Katsantonis N, Nauer RK, Lauing KL, Jagodzinski JE, Callaci JJ. Ketorolac administration does not delay early fracture healing in a juvenile rat model: a pilot study. J Pediatr Orthop. 2013 Jun;33(4):415-21. doi: 10.1097/BPO.0b013e318288b46f

19. Gomes SP, Deliberador TM, Gonzaga CC, Klug LG, Oliveira LC, Urban CA, Zielak JC, Giovanini AF. Bone healing in critical-size defects treated with immediate transplant of fragmented autogenous white adipose tissue. J Craniofac Surg. 2012 Sep;23(5):1239-44. PMID: 22948634

20. Silva MAD, Pereira AC, Marin MCC, Salgado MAC. The influence of topic and systemic administration of copaiba oil on the alveolar wound healing after tooth extraction in rats. J Clin Exp Dent. 2013 Oct;5(4):e169-73. doi: 10.4317/jced.51104.

\section{Acknowledgements}

CEELBIO for providing the bioglass and EMBRAPA by the copaiba oil. 
Silva PF et al.

\section{Correspondence:}

Priscilla Flores Silva

Travessa Nove de Janeiro, 590/601

66060-370 Belém - PA Brasil

Tel.: (55 91)8144-0777

priscilla.fsilva@yahoo.com.br

Received: Oct 15, 2014

Review: Dec 17, 2014

Accepted: Jan 19, 2015

Conflict of interest: none

Financial source: none

${ }^{1}$ Research performed at Experimental Surgery Laboratory (LCE), Para State University (UEPA), Brazil. Part of Master degree thesis, Postgraduate Program in Clinical Dentistry, UFPA. Tutor: Marcus Vinicius Henriques Brito. 